\title{
Effects of Dietary Bamboo Charcoal on the Carcass Characteristics and Meat Quality of Fattening Pigs
}

\author{
Gyo Moon Chu', Jong Hyun Kim, Sung Nam Kang ${ }^{1}$, and Young Min Song* \\ Department of Animal Resource Technology, Gyeongnam National University of Science and Technology, Jinju 660-758, Korea \\ ${ }^{1}$ Swine Science \& Technology Center, Gyeongnam National University of Science and Technology, Jinju 660-758, Korea
}

\begin{abstract}
The purpose of this study was to investage the effects of dietary bamboo charcoal on the carcass characteristics and meat quality of fattening pigs. Fifty four crossed pigs of $61.0 \pm 1.0 \mathrm{~kg}$ body weight (BW) were grouped and housed in 6 animals ( 3 barrows and 3 gilts) per pen and 3 replications per treatment. The basal diet (C) was supplied with $0.3 \%$ bamboo charcoal as treatment 1 (T1) and $0.6 \%$ as treatment 2 (T2). The pigs were fed that experimental diet for 42 days, thereafter 10 longissimus dorsi (LD) per treatment were randomly collected at the time the pigs reached an average weight of $110.0 \pm 5.0 \mathrm{~kg}$. The carcass weight, backfat thickness, and the carcass grade were better $(p<0.05)$ in the pigs fed bamboo charcoal than in $\mathrm{C}$. The crude fat concentration of LD was higher $(p<0.05)$ in T1 than in $\mathrm{C}$. While the composition of stearic acid and arachidonic acid was lower $(p<0.05)$ in treatments than in $\mathrm{C}$, the composition of oleic acid and linoleic acid of treatments was higher $(p<0.05)$ than $\mathrm{C}$. The physico-chemical characteristics, such as meat color and amino acid composition of LD were not affected $(p>0.05)$ by the supplemented bamboo charcoal. In conclusion, dietary supplementation with bamboo charcoal improved the carcass grade and fatty acids composition of pork meat from fattening pigs, where the composition of unsaturated fatty acids was increased, but that of saturated fatty acids was decreased.
\end{abstract}

Key words: bamboo charcoal, carcass grade, meat quality, pigs

\section{Introduction}

Charcoal generally refers to the carbonaceous residues left over after heating organic matter in the absence of oxygen, such as wood, coconut shells and various industrial wastes. Charcoal is an adsorbent for many toxins, gases, drugs, fat and fat-soluble substances (Kutlu et al., 2001). The adsorptive power of charcoal could be increased considerably by treating it with various substances at temperatures ranging from 500 to $900^{\circ} \mathrm{C}$ (Osol, 1975).

Some researchers explored charcoal as an animal's feed additives. Dietary supplemented with charcoal affected growth performance and carcass traits in fattening pigs (Hwang, 1995), and it also affected microbes reproduction in sheep (Knutson et al., 2006), meat quality and storage characteristics of pork (Hwang, 1995). Charcoal controls the lactic acid concentration by maintaining the $\mathrm{pH}$ level and microflora population in rumen animals

*Corresponding author: Young Min Song, Department of Animal Resources Technology, Gyeongnam National University of Science and Technology, Jinju 660-758, Korea. Tel: 82-55-751-3588, Fax: 82-55-751-3689, E-mail: pigsong@gntech.ac.kr
(Hoshi et al., 1991). It also combines with the phenol in gastrointestinal tracks, which prevents the interference of hydro-soluble tannins with enzyme's functionality and protein digestion (Murdiati et al., 1991).

Bamboo charcoal is an activated charcoal made from thick stems of bamboo by dry distillation and powdered (Zhao et al., 2008). Bamboo charcoal powder has been used as an oral antidote to reduce swallowed poisons in the gastrointestinal tracts (Anjaneyulu et al., 1993). Dietary containing $0.3 \%$ bamboo charcoal was reported to increase the growth performance, feed efficiency and beneficial fecal microflora, but at the same time, decrease noxious gas emission and harmful fecal microflora in fattening pigs (Chu et al., 2013a). Moreover, it was reported that bamboo charcoal was able to improve swine production by enhancing the feeding environment of fattening pigs and this material can be regarded as a secure feed additive and an alternative to antibiotics in animal production. Chu et al. (2013b) reported that dietary of bamboo charcoal increased growth performance, feed efficiency and immunoglobulin concentration of plasma in fattening pigs. This expected that dietary of bamboo charcoal would improve swine production due to its ability to 
improve gastrointestinal environment. Therefore, bamboo charcoal can be used as a feed additive in swine industry.

However, to our knowledge, there are no reports on the effects of bamboo charcoal in diet on the carcass characteristics and meat quality in pigs. Hence, this study was conducted to investigate the effects of additive bamboo charcoal in diet of fattening pigs on the carcass characteristics and meat quality.

\section{Materials and Methods}

\section{Processing of bamboo charcoal}

Bamboo charcoal preparation was provided by Borim Inc. (Jinju, Korea). The detailed process of bamboo charcoal was divided into 3 steps; 1) Bamboo (Phyllostachys pubescens) chips of $1 \mathrm{~cm}$ (width) $\times 2 \mathrm{~cm}$ (length) were heated at $700^{\circ} \mathrm{C}$ for $6 \mathrm{~h}$ and cooled down to room temperature (RT) to produce ashed bamboo, 2) then ashed bamboo was transferred to a rotary furnace and heated at $900^{\circ} \mathrm{C}$ for $8 \mathrm{~h}$ and cooled to RT to form activated charcoal and 3 ) the activated bamboo charcoal was ground to less than 200 mesh (less than $100 \mu \mathrm{m}$ in diameter) by jet mill.

\section{Animals and diets}

Experimental pigs were at the age of approximately 120 $\pm 1 \mathrm{~d}$ and an average body weight (BW) of $61.0 \pm 1.0 \mathrm{~kg}$ at initiation. Fifty four crossed pigs (Landrance $\times$ Yorkshire $\times$ Duroc) were assigned to 3 dietary treatments and each treatment contained 6 pigs ( 3 barrows and 3 gilts) per pen and 3 replication ( 6 pigs $\times 3$ diets $\times 3$ replications). They were given pre-feeding for $3 \mathrm{~d}$ then fed experimental diet for $42 \mathrm{~d}$ (until $110.0 \pm 5.0 \mathrm{~kg}$ of BW) and had free access to water. The Guide for Care and Use of Laboratory Animals (Animal Care Committee of Gyeongnam National University of Science and Technology) was followed in this study.

A basal diet made of $51.80 \%$ corn, $14.59 \%$ wheat, $11.12 \%$ soybean meal, $7.00 \%$ dried distiller's grains with solubles (DDGS) and $15.49 \%$ other feedstuffs or additives. Chemically, the basal diet consisted of $14.00 \%$ crude protein, $3.125 \mathrm{Mcal} / \mathrm{kg}$ metabolizable energy (ME), 0.80\% lysine and $0.40 \%$ total phosphorus. The basal diet (C) supplied with $0.3 \%$ (T1) and $0.6 \%$ (T2) bamboo charcoal.

\section{Carcass traits and carcass grades}

At the end of this experiment, the pigs were transported to a normal abattoir near the experimental station. They were electrically stunned (300 volts for $3 \mathrm{~s}$ ) for slaughter after $12 \mathrm{~h}$ from the time of feed restriction. The shocked pigs were exsanguinated while being hanged, and then
Table 1. Effects of dietary bamboo charcoal on the carcass characteristics and meat grade in fattening pigs

\begin{tabular}{lcccc}
\hline \hline \multirow{2}{*}{ Item } & \multicolumn{3}{c}{ Treatment $^{1}$} & \multirow{2}{*}{ SEM $^{2}$} \\
\cline { 2 - 4 } & $\mathrm{C}$ & $\mathrm{T} 1$ & $\mathrm{~T} 2$ & \\
\hline Carcass characteristics & & & & \\
Finished body weight, kg & $109.67^{\mathrm{b}}$ & $116.83^{\mathrm{a}}$ & $113.33^{\mathrm{a}}$ & 1.87 \\
Carcass weight, kg & $80.94^{\mathrm{b}}$ & $85.39^{\mathrm{a}}$ & $83.12^{\mathrm{a}}$ & 1.78 \\
Dressing, \% & 73.80 & 73.09 & 73.34 & 1.02 \\
Backfat thickness, mm $^{18.67^{\mathrm{b}}}$ & $22.50^{\mathrm{a}}$ & $22.00^{\mathrm{a}}$ & 2.07 \\
\hline Meat grade & $1.50^{\mathrm{a}}$ & $1.00^{\mathrm{b}}$ & $1.00^{\mathrm{b}}$ & 0.14 \\
Carcass grade $^{3}$ & 1.67 & 1.50 & 1.67 & 0.39 \\
Conformation terms $^{3}$ & 50.0 & 81.0 & 83.0 & - \\
High grade rate $^{4}, \%$ & &
\end{tabular}

${ }^{1}$ The basal diet was supplied with bamboo charcoal: $\mathrm{C}$, no supplementation; $\mathrm{T} 1,0.3 \%$ and $\mathrm{T} 2,0.6 \%$.

${ }^{2}$ Standard error of the means.

${ }^{3}$ The carcass grade and conformation terms were assessed on 4 points: 1 , extremely good (1+ grade of KAPE); 2 , good (1 grade of KAPE); 3, bad (2 grade of KAPE) and 4, extremely bad (3 grade of KAPE).

${ }^{4}$ The high grade rate was $1(1+$ grade of KAPE) plus 2 points $(1$ grade of KAPE) of carcass grade.

${ }_{\mathrm{a}, \mathrm{b}}$ Values in the same row with different superscripts differ at $p<0.05$.

the carcasses were placed in a dehairer at $62^{\circ} \mathrm{C}$ for $5 \mathrm{~min}$ and remaining hair was removed using a knife and flame. Carcasses were eviscerated and split before being placed in a chiller set at $5^{\circ} \mathrm{C}$ for $12 \mathrm{~h}$.

Pork carcasses in Korea are graded both in quality and conformation terms. The grade system of Korea Institute for Animal Products Quality Evaluation (KAPE, 2009) grades the quality of pork carcasses as 1+, 1, 2 and 3 based on the marbling, lean color and conditions of belly streaks. However in this study, pork carcasses were graded as 1 (extremely good; $1+$ grade of KAPE), 2 (good; 1 grade of KAPE), 3 (bad; 2 grade of KAPE) and 4 (extremely bad; 3 grade of KAPE). The conformation of a pork carcass is graded as A, B, C and D by assessing carcass weight, backfat thickness, balance, muscle, fat condition and so on, which was followed in this study.

The percentage of dressing was calculated as the ratio of cold carcass weight to live weight. Backfat thickness was measured using the 10th rib at three-quarters the distance along longissimus dorsi (LD) towards the belly.

\section{Sampling of longissimus dorsi and basic analysis}

The LD (6th to 13th rib) was cut off and randomly collected from 10 pigs ( 5 barrows and 5 gilts) in each treatment and kept at $5^{\circ} \mathrm{C}$ before it was transported to the laboratory to determine its chemical composition. The $\mathrm{pH}$, water holding capacity (WHC), cooking loss, shear force and meat color of LD were determined about $24 \mathrm{~h}$ after slaughter. Additionally, to determine the thiobarbituric acid 
reactive substances (TBARS) and volatile basic nitrogen (VBN), samples were vacuum-packaged, stored at $4^{\circ} \mathrm{C}$ and then analyzed on $7 \mathrm{wk}$ of storage. The LD was frozenstored at $-60^{\circ} \mathrm{C}$ for approximate analysis, fatty acid composition and amino acid composition. The approximate analysis of moisture, crude protein, crude fat and ash concentration of LD were determined according to the methods of AOAC (2000).

\section{Physicochemical characteristics}

To determine the $\mathrm{pH}$ value, a sample of $5 \mathrm{~g}$ was homogenized about $24 \mathrm{~h}$ postmortem in 10 volumes of distilled water (DW) for $20 \mathrm{~s}$ at $13,500 \mathrm{rpm}$ using a polytron homogenizer (T25B, IKA, Malaysia). Hanna HI 9025 pH meter (Woonsocket, USA) with an Orion 8163 glass electrode (Berverly, USA) was used to determine $\mathrm{pH}$ values.

Water holding capacity (WHC) was determined as described by Honikel (1998). For the cooking loss, $80 \mathrm{~g}$ of $1.5 \mathrm{~cm}$ thick LD were placed in polyethylene bags. The packages were then kept in a water bath (DS-23S, Dasol, Korea) at $75^{\circ} \mathrm{C}$ for $1 \mathrm{~h}$ and cooled at RT for $30 \mathrm{~min}$. The percentage of cooking loss was determined using muscle weight that was taken before and after cooking.

Shear force was determined as described by Honikel (1998). Each LD was prepared into a cube of $4 \mathrm{~cm} \times 2.5$ $\mathrm{cm} \times 1.5 \mathrm{~cm}$ (length $\times$ width $\times$ height) and then cooked and cooled. The shear force was measured using an Instron 3343 (US/MX50, A\&D Co., USA) equipped with a WarnerBratzler shearing device providing a $100 \mathrm{~mm} / \mathrm{min}$ crosshead speed. The average shear force value from each treatment was calculated and expressed as $\mathrm{kg} / \mathrm{cm}^{2}$.

The VBN as protein degradation analysis was conducted as described by Pearson (1976) and expressed as mg VBN per $100 \mathrm{~g}$ of sample. Briefly, $1 \mathrm{~g}$ of sample and a few drops of phenolphthalein indicator were mixed with a $3.5 \mathrm{~mL} 20 \%$ sodium hydroxide solution in a distillated flask. The apparatus was tightly sealed, and steam distillate was collected in a flask containing a $20 \mathrm{~mL}$ of $4 \%$ boric acid and a few drops of methyl red and methylene blue. The steam distillate was continuously collected until a $250 \mathrm{~mL}$ distillated flask was filled. The solution obtained was then titrated using a $0.01 \mathrm{M}$ hydrochloric acid and titration was stopped when the green color changed to gray. The final VBN calculation was accomplished based on a VBN value from a blank containing $6 \%$ perchloric acid steam distillation.

The TBARS analysis described by Huang and Miller (1993) was performed to determine the degree of lipid oxidation. The $3 \mathrm{~g}$ of each meat sample was weighed and mixed with a $57 \mathrm{~mL}$ phosphate buffer ( $\mathrm{pH} 7.0)$. The mixtures were then homogenized at 12,000 $\mathrm{g}$ for $1 \mathrm{~min}$ (T25B, IKA, Malaysia). The homogenized samples were incubated, cooled and centrifuged at 2,000 rpm for $15 \mathrm{~min}$. The supernatants were collected, read, calculated and expressed as mg malonaldehyde (MA) per kg of LD muscle tissue.

\section{Meat surface color}

Meat color of LD was evaluated on freshly cut surface ( $3 \mathrm{~cm}$ thick slice) using a Chroma Meter CR-300 (Minolta, Japan) after $20 \mathrm{~min}$ at room temperature. Three color measurements were carried out across individual sample surfaces and the average of five replicates was expressed as CIE L*, CIE a*, CIE b*, chroma and hue angel. The CIE is defined international commission on illumination (usually abbreviated CIE for its French name as commission international de l' éclairage). The Chroma Meter CR-300 was calibrated against a white tile $\left(\mathrm{L}^{*}=89.20, \mathrm{a}^{*}=0.921\right.$ and $\mathrm{b}^{*}=0.783$ ). The aperture was $8 \mathrm{~mm}$, illuminant D65 and $10^{\circ}$ Standard Observer. Chroma (saturation) was calculated as $\left(\mathrm{a}^{* 2}+\mathrm{b}^{* 2}\right)^{1 / 2}$, and hue angle was calculated as $\arctan \mathrm{b}^{*} / \mathrm{a}^{*}$ (Wyszcecki and Stiles, 1982).

\section{Fatty acid composition}

To determine fatty acids composition, the total lipid was extracted as described by Ways and Hanahan (1964), and then saponification and esterification was conducted using a $0.5 \mathrm{~N}$ potassium hydroxide in methanol and $14 \%$ boron trifluoride methanol solution. At the end, the fatty acids methyl esters (FAME) in the hexane were injected to a gas chromatography (Agilent 6890+, Agilent HP, USA) fitted with a capillary column (HP-5MS capillary GLC column, $30 \mathrm{~m} \times 0.32 \mathrm{~mm}$ i.d. $0.25 \mathrm{~mm}$ film thickness, Agilent HP, USA) and a mass spectrometry detector (G1530A, Agilent HP, USA).

The mass spectrometry interface and injector temperature were fixed at $270^{\circ} \mathrm{C}$ and $260^{\circ} \mathrm{C}$, respectively. The oven temperature was instituted to $160^{\circ} \mathrm{C}$ for $2.5 \mathrm{~min}, 160$ to $260^{\circ} \mathrm{C}$ at $4^{\circ} \mathrm{C}$ per min and then $260^{\circ} \mathrm{C}$ for $5 \mathrm{~min}$. Each fatty acid was identified by comparing its retention time with that of FAME standard (FAME Mix C8-C24, Supelco, USA) and expressed as a percentage of the standard.

\section{Amino acid composition}

A $100 \mathrm{mg}$ sample of each LD was added to $3 \mathrm{~mL}$ of $6 \mathrm{~N}$ hydrochloric acid then packed in nitrogen gas. The packed samples were hydrolyzed at $110^{\circ} \mathrm{C}$ for $24 \mathrm{~h}$ and then removed from the hydrochloric acid. The enriched samples 
were added to $5 \mathrm{~mL}$ of $1 \mathrm{M}$ sodium citrate buffer $(\mathrm{pH} 2.2)$ and filtered through $0.2 \mu \mathrm{m}$ membranes. The amino acid composition was measured with an amino acid auto analyzer (Biochrom 20, Olympus, Japan).

\section{Texture profile analysis}

Texture profile analysis (TPA) of ten samples of 2.00 $\mathrm{cm} \times 2.00 \mathrm{~cm} \times 2.00 \mathrm{~cm}$ (length $\times$ width $\times$ height $)$ from each treatment and then cooked and cooled. The cooked sample was assessed using an Instron 3343(US/MX50, A\&D Co., USA) equipped with a cylindrically shaped plunger (5-mm diameter) and a $500 \mathrm{~N}$ load cell (Bourne, 1978; Szczceniak, 1963). To determine texture parameters including hardness, cohesiveness, springiness, gumminess, chewiness and adhesiveness, each sample cube was equilibrated to a room temperature and compressed twice to $50 \%$ of its original thickness at a constant speed of $60 \mathrm{~mm} / \mathrm{min}$.

Texture profile parameters were calculated from the force deformation curves as follows: hardness $(\mathrm{kg} \mathrm{f}$; force necessary to attain a given deformation, maximum force), cohesiveness (dimensionless, ratio; ratio of the positive force area during the second compression to that during the first compression excluding the areas under the decompression portion of each cycle), springiness (ratio; ratio of distances that the sample recover after the first compression), gumminess ( $\mathrm{kg} \mathrm{f}$; simulated energy required to disintegrate a semisolid food to a steady state, hardness $x$ cohesiveness) and chewiness (kg f; hardness $\times$ cohesiveness $\times$ springiness).

\section{Statistical analyses}

The collected data was analyzed with one-way ANOVA. The General Linear Model (GLM) procedure of SAS (1999) was applied to conduct all analyses and significant differences among the means were determined using the Duncan's Multiple Range Test method (Duncan, 1955) and significant difference between means was examined at 5\% threshold.

\section{Results and Discussion}

\section{Carcass characteristics and meat grade}

Effect of dietary supplemented with bamboo charcoal on the carcass characteristics and meat grade is shown in Table 1. Although dietary of bamboo charcoal showed no effect $(p>0.05)$ on dressing, it significantly increased $(p<$ $0.05)$ the final BW, carcass weight and backfat thickness of LD.

Carcass grade was significantly improved $(p<0.05)$ in pigs fed bamboo charcoal diet compared with those fed C diet alone, and the conformation was not affected $(p>0.05)$. The ratio of high grade (1+ and 1 grades of KAPE) was higher in pigs fed bamboo charcoal diet and the highest grade was in T2 group with $0.6 \%$ bamboo charcoal.

Chu et al. (2013b) reported that dietary of bamboo charcoal increased the average daily gain and feed efficiency in fattening pigs due to increased villus size (Lauronen et al., 1998). Moreover, the lower nutritional value of the experimental diet decreased carcass weight and backfat thickness (Chu et al., 2011). These studies support the findings of the present study where bamboo charcoal increased the final BW and carcass weight due to an increased average daily gain and feed efficiency, which was a result of improved nutrient utilization due to increased microscopic parameters, such as protuberated cells by increased villi size and epithelial cells in fattening pigs (Kutlu et al., 2001).

Bamboo charcoal improved the carcass and ratio of high carcass grade in the present experiment. In Korea, carcasses are graded in a standard based on many factors such as, carcass weight, backfat thickness, balance, muscle, fat condition and etc (KAPE, 2009). The best carcass grade of pork is when the weight ranges between 84 to $94 \mathrm{~kg}$ with 18 to $25 \mathrm{~mm}$ backfat thickness of LD (KAPE, 2009). The LD of fattening pigs fed supplemental bamboo charcoal showed optimal ranges of carcass weight and backfat thickness in this experiment.

\section{Proximate analysis and physico-chemical characteri- stics}

The proximate analysis and physico-chemical characteristics of LD from fattening pigs fed bamboo charcoal are shown in Table 2. The experimental dietary of bamboo charcoal showed no effect $(p>0.05)$ on the concentration of moisture, crude protein and ash, but significantly affected $(p<0.05)$ the crude fat concentration, which was significantly higher $(p<0.05)$ in $\mathrm{T} 1$ than in $\mathrm{C}$.

Typically, the consumption of diet with high energy and fat was found to increase backfat thickness (Pettigrew and Moser 1991) and crude fat concentration of LD (Kang et al., 2010). Song et al. (2011) reported that the low concentration of crude fat and diet with low total calorie decreased the crude fat concentration of LD in fattening pigs. The dietary of 0.3 and $0.6 \%$ bamboo charcoal increased 1.54 and $0.74 \%$ of crude fat concentration of LD in present experiment. Therefore, diet with bamboo charcoal may have increased the crude fat concentration of LD as a result of improved nutrient utilization in fattening pigs, 
Table 2. Effects of dietary bamboo charcoal on proximate analysis and phsico-chemical characteristics of longissimus dorsi in fattening pigs

\begin{tabular}{lcccc}
\hline \hline \multirow{2}{*}{ Items } & \multicolumn{3}{c}{ Treatment $^{1}$} & \multirow{2}{*}{ SEM $^{2}$} \\
\cline { 2 - 4 } & $\mathrm{C}$ & $\mathrm{T} 1$ & $\mathrm{~T} 2$ & \\
\hline Proximate analysis, \% & & & & \\
Moisture & 70.60 & 69.55 & 69.98 & 0.26 \\
Crude protein & 22.77 & 22.22 & 22.40 & 0.23 \\
Crude fat & $7.83^{\mathrm{b}}$ & $9.37^{\mathrm{a}}$ & $8.57^{\mathrm{ab}}$ & 0.34 \\
Ash & 1.04 & 0.95 & 1.21 & 0.03 \\
\hline Physico-chemical characteristics & & & \\
pH & 5.250 & 5.332 & 5.228 & 0.061 \\
Water holding capacity, \% & 22.20 & 26.04 & 22.82 & 3.26 \\
Cooking loss, \% & 38.96 & 37.46 & 36.23 & 1.17 \\
Shear fore, kg/cm ${ }^{2}$ & 3.03 & 3.18 & 3.94 & 0.31 \\
Drip loss, \% & 3.05 & 2.98 & 5.79 & 1.26 \\
Volatile basic nitrogen, & 5.731 & 5.936 & 6.972 & 0.889 \\
mg/100g & & & & \\
TBARS ${ }^{3}$, mg & 0.398 & 0.357 & 0.369 & 0.021 \\
malonaldehyde/kg & & & & \\
\hline
\end{tabular}

${ }^{1}$ The basal diet was supplied with bamboo charcoal: C, no supplementation; T1, 0.3\%; and T2, 0.6\%.

${ }^{2}$ Standard error of the means.

${ }^{3}$ Thiobarbituric acid reactive substances.

${ }^{\mathrm{a}, \mathrm{b}}$ Values in the same row with different superscripts differ at $p<0.05$.

which increased the backfat thickness.

The experimental dietary of bamboo charcoal did not affect $(p>0.05)$ the physic-chemical characteristics, such as $\mathrm{pH}$, WHC, cooking loss, shear force, VBN and TBARS of LD from fattening pigs.

The $\mathrm{pH}$ of meat is changed by nutrient (Rosenvold et al., 2003) and energy values of diet, which affect the concentration of macro-glycogen in muscles and change the glycolysis and cooling rate of meat (McDonagh et al., 1999; Rosenvold et al., 2001). In the current study, the concentration of glycogen was not measured, but it is well known that an increased $\mathrm{pH}$ is a result of a decreased glycogen concentration in meat (Rosenvold et al., 2001). In this report, the bamboo charcoal in diet showed no effect on the $\mathrm{pH}$ of meat, because the energy values of diet were not different between treatments.

The WHC is an important factor in the quality of fresh pork and affected by many factors after slaughter (Kwon et al., 1995). Cooking loss of meat is affected by soluble creatine and soluble fat (Carlin et al., 1965). Up to now, the effects of charcoal or activated charcoal on the WHC, cooking loss or shear force are not well understood (Hwang, 1995).

The VBN such as protein degradation is an important index for estimation of meat freshness, because it is increased by the levels of microbial contamination. Meat protein is degraded into amino acids by protease and enzymes from microorganisms and amino acids in turn are degraded into inorganic nitrogen compounds when the levels of microorganism contamination are increased (Lee et al., 2006). The protein degradation of breast meat from broilers is not affected by activated charcoal (Kim and Park, 2001) or in pork of fattening pigs (Hwang, 1995). These reports agree with results of the present experiment as bamboo charcoal expressed no effect on protein degradation of LD in fattening pigs.

The TBARS such as lipid oxidation is affected by various factors including storage period and temperature, fatty acids composition, active oxygen and antioxidants (Chen and Wailmaleongoraek, 1981). Usually, a dietary with high contents of poly-UFA is more prone to oxidation and a dietary of high antioxidant contents, such as vitamins, carotenoids and flavonoids, protects the meat against lipid oxidation (Paiva-Martins et al., 2009). However, bamboo charcoal did not affect lipid oxidation of pork in this study.

\section{Meat color}

The effect of dietary bamboo charcoal on the meat color and backfat color is shown in Table 3. Dietary with bamboo charcoal did not show significant effects $(p>0.05)$ on CIE a* (redness), CIE L* (lightness), CIE b* (yellowness), chroma and hue angel of LD from fattening pigs. Moreover, the dietary of bamboo charcoal did not significantly $(p>0.05)$ affect the surface color (lightness, redness and yellowness) of the backfat.

Meat color is an important factor of pork quality and the most important factor that appeals to consumers who prefer high redness of pork. Meat color is mainly affected by $\mathrm{pH}$ and temperature of meat during the slaughter process (Lindahl et al., 2006). In this study, dietary of bamboo charcoal did not change the lightness, redness and yellowness of pork, which was suggested by Hwang (1995) who reported that a dietary supplemented with charcoal did not affect the meat color of pork from fattening pigs.

\section{Fatty acid composition}

The composition of the oleic acid and linoleic acid from the LD of fattening pigs was significantly increased $(p<$ 0.05 ) by the dietary of bamboo charcoal, but the composition of myristic acid, palmitoleic acid and linolenic acid was not significantly affected $(p>0.05)$ and the stearic acid and arachidonic acid composition was significantly decreased $(p<0.05)$. The oleic acid composition was highly significant $(p<0.05)$ in T1 compared with other treatments. The composition of saturated fatty acid (SFA) was significantly lower $(p<0.05)$ in treatments than in $\mathrm{C}$ and it was 
Table 3. Effects of dietary bamboo charcoal on meat color $^{1}$ and backfat color ${ }^{1}$ of longissimus dorsi in fattening pigs

\begin{tabular}{lcccc}
\hline \hline \multirow{2}{*}{ Item } & \multicolumn{3}{c}{ Treatment $^{2}$} & \multirow{2}{*}{ SEM $^{3}$} \\
\cline { 2 - 4 } & $\mathrm{C}$ & $\mathrm{T} 1$ & $\mathrm{~T} 2$ & \\
\hline Meat color & & & & \\
$\mathrm{CIE} \mathrm{L}^{*}$ & 56.81 & 55.78 & 55.38 & 0.98 \\
$\mathrm{CIE} \mathrm{a}^{*}$ & 2.04 & 2.37 & 2.76 & 0.37 \\
$\mathrm{CIE} \mathrm{b}^{*}$ & 4.00 & 3.87 & 4.18 & 0.28 \\
Chroma & 4.53 & 4.61 & 5.04 & 0.36 \\
Hue angle & 63.60 & 60.49 & 47.37 & 5.62 \\
\hline Backfat color & & & & \\
CIE L* & 80.83 & 80.92 & 80.62 & 0.46 \\
CIE a* & -0.58 & -0.90 & -1.27 & 0.27 \\
CIE b* & 7.63 & 7.02 & 7.04 & 0.18 \\
Chroma & 7.67 & 7.18 & 7.17 & 0.16 \\
Hue angle & 94.47 & 97.62 & 100.21 & 2.31 \\
\hline
\end{tabular}

${ }^{1}$ CIE L*, black (0) to white (100) color scale; CIE a*, red (+) to green $(-)$ color scale; CIE $b^{*}$, yellow $(+)$ to blue $(-)$ color scale;

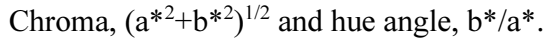

${ }^{2}$ The basal diet was supplied with bamboo charcoal: $\mathrm{C}$, no supplementation; T1, 0.3\%; and T2, 0.6\%.

${ }^{3}$ Standard error of the means.

Table 4. Effects of dietary bamboo charcoal on fatty acid composition of longissimus dorsi in fattening pigs

\begin{tabular}{lcccc}
\hline \hline \multirow{2}{*}{ Items } & \multicolumn{3}{c}{ Treatment $^{\mathrm{I}}$} & \multirow{2}{*}{ SEM $^{2}$} \\
\cline { 2 - 4 } & $\mathrm{C}$ & $\mathrm{T} 1$ & $\mathrm{~T} 2$ & \\
\hline Fatty acid composition, \% & & & & \\
Myristic acid & 1.01 & 1.24 & 1.25 & 0.10 \\
Palmitic acid & $21.38^{\mathrm{b}}$ & $22.36^{\mathrm{ab}}$ & $23.08^{\mathrm{a}}$ & 0.41 \\
Palmitoleic acid & 3.10 & 2.52 & 2.99 & 0.21 \\
Stearic acid & $18.82^{\mathrm{a}}$ & $13.38^{\mathrm{b}}$ & $14.71^{\mathrm{b}}$ & 0.65 \\
Oleic acid & $41.25^{\mathrm{c}}$ & $46.08^{\mathrm{a}}$ & $43.53^{\mathrm{b}}$ & 0.48 \\
Linoleic acid & $9.68^{\mathrm{b}}$ & $11.23^{\mathrm{a}}$ & $11.04^{\mathrm{a}}$ & 0.34 \\
Linolenic acid & 0.83 & 0.86 & 0.85 & 0.09 \\
Arachidonic acid & $3.95^{\mathrm{a}}$ & $2.33^{\mathrm{b}}$ & $2.44^{\mathrm{b}}$ & 0.29 \\
\hline Saturated fatty acid (SFA) & $41.63^{\mathrm{a}}$ & $37.44^{\mathrm{c}}$ & $39.42^{\mathrm{b}}$ & 0.49 \\
Unsaturated fatty acid (USFA) & $58.37^{\mathrm{b}}$ & $62.56^{\mathrm{a}}$ & $60.58^{\mathrm{ab}}$ & 0.49 \\
Essential fatty acid & 11.51 & 12.90 & 12.89 & 0.27 \\
USFA/SFA & $1.40^{\mathrm{b}}$ & $1.67^{\mathrm{a}}$ & $1.54^{\mathrm{a}}$ & 0.03 \\
\hline
\end{tabular}

${ }^{1}$ The basal diet was supplied with bamboo charcoal: $\mathrm{C}$, no supplementation; $\mathrm{T} 1,0.3 \%$; and $\mathrm{T} 2,0.6 \%$.

${ }^{2}$ Standard error of the means.

a,b,c Values in the same row with different superscripts differ at $p<$ 0.05 .

lowest $(p<0.05)$ in $\mathrm{T} 1$, while the ratio of unsaturated fatty acid (USFA) to SFA (USFA/SFA) was significantly higher $(p<0.05)$ in treatments than in C. The USFA composition was significantly higher $(p<0.05)$ in $\mathrm{T} 1$ than in $\mathrm{C}$, though the dietary of bamboo charcoal had no effect $(p>0.05)$ on the composition of essential fatty acids (EFA) and the ratio of SFA to USFA of LD (Table 4).

The fatty acids composition of LD is changed by diet in monogastric animals (Pascual et al., 2007). In this study, the nutrient values of diet were not different between $\mathrm{C}$ and treatments, but the diet of treatment might have increased nutrient utilization (Kutlu et al., 2001). A high level of USFA and low level of SFA in LD is more beneficial to human health, such as prevention of arteriosclerosis and hypertension (Decker and Shantha, 1994; Engler et al., 1991). Therefore, based on the results of this study, a dietary supplemented with bamboo charcoal improved the fatty acid composition of LD from fattening pigs in away that might be beneficial to human health. The benefits might come from the ability of the diet to increase USFA and decrease SFA composition of LD in fattening pigs.

\section{Amino acid composition}

Dietary of bamboo charcoal did not affect $(p>0.05)$ the composition of essential amino acids including arginine, histidine, isoleucine, leucine, lysine, methionine, phenylalanine, threnonine and valine. Additionally, the dietary did not affect the composition of unessential amino acids including alanine, aspartic acid, cysteine, glutamic acid, glycine, proline, serine and tyrosine in the LD of fattening pigs (Table 5).

Dietary of bamboo charcoal was not observed on the amino acid composition of LD and the reason is unknown. Therefore, further study is still warrant to make a conclusion about the effects of bamboo charcoal on the amino acid composition of LD. However, no difference was observed with fermented diet in pigs. In contrast, a fermented diet did not affect the amino acid composition of LD in pigs (Chu et al., 2011) as well as a high-carbohydratelow-fat diet (Kang et al., 2010) in agreement with the results of the present study.

\section{Texture profile analysis}

The dietary of bamboo charcoal did not affect $(p>0.05)$ the texture profile analysis that includes hardness, cohesiveness, springiness, gumminess, chewiness and adhesiveness of LD in fattening pigs (Table 6).

Tenderness of meat is the most important factor for evaluation of pork meat and animal products, though appearance, meat color, flavor, taste and juiciness are also important factors to consumers (Bailey, 1972). It was not reported that dietary of charcoal, activated charcoal or bamboo charcoal had any effect on TPA of LD from pigs. However, TPA of LD was greatly affected by fatty acids composition, while tenderness and juiciness of meat were correlated with the concentration of crude fat, WHC and cooking loss (Wood et al., 2008). In this study, the dietary 
Table 5. Effects of dietary bamboo charcoal on amino acid composition of longissimus dorsi in fattening pigs

\begin{tabular}{lcccc}
\hline \hline \multirow{2}{*}{ Items } & \multicolumn{3}{c}{ Treatment $^{1}$} & \multirow{2}{*}{ SEM $^{2}$} \\
\cline { 2 - 4 } & $\mathrm{C}$ & $\mathrm{T} 1$ & $\mathrm{~T} 2$ & \\
\hline Essential amino acid, \% & 8.644 & 8.867 & 8.563 & 0.330 \\
Arginine & 1.100 & 1.137 & 1.107 & 0.046 \\
Histidine & 1.658 & 1.735 & 1.631 & 0.067 \\
Isoleucine & 0.806 & 0.828 & 0.812 & 0.030 \\
Leucine & 1.427 & 1.483 & 1.407 & 0.059 \\
Lysine & 0.759 & 0.759 & 0.758 & 0.023 \\
Methionine & 0.463 & 0.434 & 0.455 & 0.029 \\
Phenylalanine & 0.746 & 0.749 & 0.717 & 0.032 \\
Threonine & 0.833 & 0.864 & 0.816 & 0.031 \\
Valine & 0.853 & 0.879 & 0.859 & 0.028 \\
\hline Unessential amino acid, \% & 8.107 & 8.402 & 7.981 & 0.296 \\
Alanine & 0.990 & 1.034 & 0.981 & 0.038 \\
Aspartic acid & 1.642 & 1.719 & 1.623 & 0.061 \\
Cystine & 0.127 & 0.119 & 0.127 & 0.007 \\
Glutamic acid & 2.591 & 2.706 & 2.562 & 0.088 \\
Glysine & 0.733 & 0.825 & 0.747 & 0.030 \\
Proline & 0.702 & 0.703 & 0.673 & 0.033 \\
Serine & 0.723 & 0.756 & 0.712 & 0.026 \\
Tyrosine & 0.600 & 0.539 & 0.554 & 0.035 \\
\hline Total amino acid, \% & 16.751 & 17.269 & 16.543 & 0.623 \\
\hline
\end{tabular}

${ }^{1}$ The basal diet was supplied with bamboo charcoal: $\mathrm{C}$, no supplementation; T1, $0.3 \%$; and T2, $0.6 \%$.

${ }^{2}$ Standard error of the means.

Table 6. Effects of dietary with bamboo charcoal on texture profile analysis ${ }^{1}$ of longissimus dorsi in fattening pigs

\begin{tabular}{lcccc}
\hline \hline \multirow{2}{*}{\multicolumn{1}{c}{ Items }} & \multicolumn{3}{c}{ Treatment $^{2}$} & \multirow{2}{*}{ SEM $^{3}$} \\
\cline { 2 - 4 } & $\mathrm{C}$ & $\mathrm{T} 1$ & $\mathrm{~T} 2$ & \\
\hline Hardness, kg f & 1.79 & 1.34 & 1.49 & 0.19 \\
Cohesiveness, ratio & 0.46 & 0.51 & 0.44 & 0.05 \\
Springiness, ratio & 1.07 & 1.22 & 1.05 & 0.07 \\
Gumminess, kg f & 0.85 & 0.68 & 0.67 & 0.13 \\
Chewiness, kg f & 0.92 & 0.88 & 0.72 & 0.20 \\
Adhesiveness, kg f & 0.44 & 0.28 & 0.34 & 0.07 \\
\hline
\end{tabular}

${ }^{1}$ Texture profile analysis were scored on point scale based on - (extremely soft) to + (extremely hard).

${ }^{2}$ The basal diet supplied with bamboo charcoal: $\mathrm{C}$, no supplementation; T1, 0.3\%; and T2, $0.6 \%$.

${ }^{3}$ Standard error of the means.

of bamboo charcoal did not affect the TPA of LD from fattening pigs. The experimental dietary of bamboo charcoal tested in this study might be used to produce pork from fattening pigs with appealing sensory features to consumers.

\section{Conclusion}

The results of this study indicated that the test dietary supplemented with bamboo charcoal increased the carcass weight and backfat thickness. The dietary also imp- roved the carcass grade and ratio of high carcass grade in fattening pigs. Moreover, the experimental dietary of bamboo charcoal affected the crude fat concentration. Therefore, dietary of bamboo charcoal was expected to improve swine farms income due to increased carcass prices and improved fatty acids composition (increased USFA composition and decreased SFA composition) of LD from fattening pigs.

\section{Acknowledgments}

This work was supported by the Priority Research Centers Program through the National Research Foundation of Korea (NRF) funded by the Ministry of Education, Science and Technology (2012-0006683). Also, this research was supported by iPET (Korea Institute of Planning and Evaluation for Technology in Food, Agriculture, Forestry and Fisheries), Ministry of Food, Agriculture, Forestry and Fisheries, Republic of Korea. This work was presented as a part of a master dissertation by Jong-Hyun Kim. We would like also to thank Borim Inc., Jinju Korea for their kind help with supporting materials.

\section{References}

1. Anjaneyulu, Y., Rao, P. R., and Naidu, N. R. G. (1993) Experimental aflatoxicosis and its amelioration by activated charcoal in broiler chicken-study on performance and haematology. $J$. Vet. Anim. Sci. 24, 51-54.

2. Bailey, A. J. (1972) The basis of meat texture. J. Sci. Food Agri. 23, 995-1007.

3. Bourne, M. C. (1978) Texture profile analysis. Food Tech. 32, 62-66.

4. Carlin, F. C., Bloemer, D. M., and Hotchkiss, D. K. (1965) Relation of oven temperature to quality of pork loin roasts. $J$. Home Eoon. 57, 442.

5. Chen, T. C. and Wailmaleongoraek, C. (1981) Effect of pH values of ground raw poultry meat. J. Food Sci. 46, 1946-1958.

6. Chu, G. M., Jung, C. K., Kim, H. Y., Ha, J. H., Kim, J. H., Jung, M. S., Lee, S. J., Song, Y., Ibrahim, R. I. H., Cho, J. H., Lee, S. S., and Song, Y. M. (2013a) Effects of bamboo charcoal and bamboo vinegar as antibiotic alternatives on growth performance, immune responses and fecal microflora population in fattening pigs. Anim. Sci. J. 84, 113-120.

7. Chu, G. M., Kim, J. H., Kim, H. Y., Ha, J. H., Jung, M. S., Song, Y., Cho, J. H., Lee, S. J., Ibrahim, R. I. H., Lee, S. S., and Song, Y. M. (2013b) Effects of bamboo charcoal on the growth performance, blood characteristics and noxious gas emission in fattening pigs. J. Appl. Anim. Res. 41, 48-55.

8. Chu, G. M., Yang, B. S., Kim, H. Y., Kim, J. H., Ha, J. H., Kim, C. H., Lee, S. D., and Song Y. M. (2011) Effects of supplemental fermented agro by-products diet on the growth performances, blood characteristics and carcass traits in fatten- 
ing pigs. Asian-Aust. J. Anim. Sci. 24, 1464-1472.

9. Decker, E. A. and Shantha, N. C. (1994) Concentrations of the anticarcinogen, conjugated linoleic acid in beef. Meat Focus Int. 3, 61-69.

10. Duncan, D. B. (1955) Multiple range and multiple F tests. Biometrics 11, 1.

11. Engler, N. M., Karanian, J. W., and Salem, J. M. (1991) Influence of dietary polyunsaturated fatty acids on aortic and plate fatty acid composition in the rat. Nutr. Res. 11, 753-762.

12. Honikel, K. O. (1998) Reference methods for the assessment of physical characteristics of meat. Meat Sci. 49, 447-457.

13. Hoshi, K., Yamamoto, T., Takemura, N., Sako, T., Koyama, H., and Motoyoshi, S. (1991) Effects of activated charcoal on intraruminal lactic acid. Bull. Nippon Vet. Zootech. Coll. 40, 22-28.

14. Huang, Y. X. and Miller, E. L. (1993) Iron-induced TBARS as an indicator of oxidative stability of fresh chicken meat. In: Proceedings of the 11th European symposium on the quality of poultry meat. pp. 430-434, Tours, France.

15. Hwang, M. J. (1995) Effects of activated carbon on the growth rate, feed efficiency, and carcass characteristics in pigs. $\mathrm{PhD}$. Thesis, KonKuk University, Seoul, Korea.

16. Kang, S. N., Song, Y. M., Kim, C. W., Kim, T. W., Chu, G. M., Yang, B. S., Jin, S. K., and Kim, I. S. (2010) Effect of feeding high carbohydrate-low fat fermented feed on the meat quality characteristics in finishing pigs. Korean J. Food Sci. An. 30, 826-832.

17. Kim, Y. J. and Park, C. I. (2001) Effects of additions of activated carbon on productivity and physico-chemical characteristics in broilers. Korean J. Food Sci. An. 21, 24-31.

18. Knutson, H. J., Carr, M. A., Branham, L. A., Scott, C. B., and Callaway, T. R. (2006) Effects of activated charcoal on binding E. coli $\mathrm{O} 157: \mathrm{H} 7$ and Salmonella typhimurium in sheep. Small Rum. Res. 65, 101-105.

19. Korea Institute for Animal Products Quality Evaluation (KAPE). (2009). Animal products grade system. Korea Institute for Animal Products Quality Evaluation, Gunpo, Korea.

20. Kutlu, H. R., Unsal, I., and Gorgulu, M. (2001) Effects of providing dietary wood (oak) charcoal to broiler chicks and laying hens. Anim. Feed Sci. Technol. 90, 213-226.

21. Kwon, Y. J., Yeo, J. S., and Sung, S. K. (1995) Quality characteristics of Korean native chicken meat. Kor. J. Poult. Sci. 22, 223-231.

22. Lauronen, J., Pakarinen, M. P., Kuusanmakai, P., Savilahti, E., Vento, P., Paavonen, T., and Halttunen, J. (1998) Intestinal adaptation after massive proximal small-bowel resection in the pig. Scand. J. Gastroenterol. 33, 152-158.

23. Lee, S. Y., Han, J. H., Cho, S. H., Kim, A. R., Kim, J. H., Park, S. M., and Ahn, D. H. (2006) Effect of film with water-soluble chitosan packaging on shelf-life and quality of pork lion. $J$. Chitin Chitosan. 11, 228-236.

24. Lindahl, G., Enfalt, A. C., Andersen, H. J., and Lundstrom, K. (2006) Impact of RN genotype and storage time on colour characteristics of the pork muscles longissimus dorsi and semimembranosus. Meat Sci. 74, 746-755.

25. McDonagh, M. B., Fernandez, C., and Oddy, V. H. (1999) Hindlimb protein metabolism and calpain system activity influ- ence post-mortem change in meat quality in lamb. Meat Sci. 52, 9-18.

26. Murdiati, T. D., McSweeney, C., and Lowry, J. B. (1991) Complexing of the toxic hydrolysable tannins of yellow wood (Terminalia oblongata) and harendong (Climedia hirta) with reactive substances: An approach to preventing toxicity. J. Appl. Toxicol. 11, 333-338.

27. Osol, A. (1975) Remington's Pharmaceutical Sciences, 15th edn. Mack Publishing Co., Pennsylvania, USA.

28. Paiva-Martins, F., Barbosa, S., Pinheiro, V., Mourao, J. L., and Outor-Monteiro, D. (2009) The effect of olive leaves supplementation on the feed digestibility, growth performance of pigs and quality of pork meat. Meat Sci. 82, 438-443.

29. Pascual, J. V., Rafecas, M., Canela, M. A., Boatella, J., Bou, R., and Barroeta, A. C. (2007) Effect of increasing amounts of a linoleic-rich dietary fat on the fat composition of four pig breeds. Part: Fatty acid composition in muscle and fat tissue. Food Chem. 100, 1639-1648.

30. Pearson, D. (1976). The Chemical Analysis of Foods, 7th edn. p. 386. Churchill, Livingston.

31. Pettigrew, J. J. E. and Moster, R. L. (1991) Fat in swine nutrition. Miller, R., Ullrey, D. E., and Lewis, A. J. Edn. Swine Nutrition. pp. 133-146. Butterworth-Heinemann, Stoneham, MA.

32. Rosenvold, K., Essen-Gustavsson, B., and Andersen, H. J. (2003) Dietary manipulation of pro- and macro-glycogen in porcine skeletal muscle. J. Anim. Sci. 81, 130-134.

33. Rosenvold, K., Laerke, H. N., Jensen, S. K., Karlsson, A. H., Lundström, K., and Andersen, H. J. (2001) Strategic finishing feeding as a tool in the control of pork quality. Meat Sci. 59, 397-406.

34. Skyles, A. J. and Sweet, B. (2004) Wormwood. Am. J. Health Syst. Pharm. 61, 239-241.

35. Song, Y. M., Chu, G. M., Ha, J. H., Lee, H. J., Kim, S. C., and Kim, H. Y. (2011) Effects of fermented diet using probiotics from pine needle microbes on growth performance, blood characteristics, carcass traits and economy of pigs. J. Agri. Life Sci. 45, 93-101.

36. Statistical Analysis Systems (SAS). (1999) User's Guide: Statistics Version 8th edn. SAS Institute, Cary, NC.

37. Szczceniak, A. S. (1963) Classification of textural characteristics. J. Food Sci. 28, 385-389.

38. Way, P. and Hanahan, D. J. (1964) Characterization and quantification of red cell lipids. J. Lipid Res. 5, 318-328.

39. Wood, J. D., Enser, M., Fisher, A. V., Nute, G. R., Sheard, P. R., Richardson, R. I., Hughes, S. I., and Whittington F. M. (2008) Fat deposition, fatty acid composition and meat quality: A review. Meat Sci. 78, 343-358.

40. Wyszcecki, G. and Stiles, W. S. (1982) Color science (2nd edn.). Concepts and method, quantitative data and formula. New York, John Wiley.

41. Zhao, R., Yuan, J., Jiang, T., Shi, J., and Cheng, C. (2008) Application of bamboo charcoal as solid-phase extraction adsorbent for the determination of atrazine and simazine in environmental water samples by high-performance liquid chromatography-ultraviolet detector. Talanta 76, 956- 959.

(Received 2013.3.20/Revised 2013.6.10/Accepted 2013.6.12) 